\title{
Comparative Study in Anterior Distal Hypospadias Reconstruction Utilizing Different Techniques (Mathieu and Snodgrass): Outcome, Complications and Failure Rate
}

\author{
Dr. Mazin Adday Hasoon \\ F.I.B.M.S - C.A.B.M.S\} Medical College, The-Qar University Espicilest Urologyest
}

\begin{abstract}
Purpose: To compare the outcomes of Mathieu and Snodgrass techniques in the repair of anterior distal shaft hypospadias

Materials And Methods: From march 2012 to march 2013.45 patients with the age(range1 to 12) years suffering from anterior distal shaft hypospadias, were assessed. Inclusion criteria were anterior distal shaft hypospadias, and exclusion criteria were association with chordee, circumcision, and surgical repair history. 25 patients underwent surgical repair using Snodgrass technique and 20 patients, using Mathieu technique. Surgeries were performed by one single surgeon, acquainted with both techniques. Patients were examined 1 week, and 1 month after discharge. Data including duration of the surgery, stenting time and any kind of complications such as break down, meatal stenosis, and fistula formation were collected. Also, success

Rate was calculated for every single patient and accordingly, the two groups were compared.

Results: Mean operative time, were $74 \pm 26$.minutesin Mathieu group and106.11 \pm 23 . Minutesin Snodgrass group $(P<0.05)$.stenting duration $6.8 \pm 1.1$ days, in Mathieu group and, $6.3 \pm 0.8$ daysin Snodgrass group $(P$ $>0.05$ ). The rate of break down, meatal stenosis, and fistula formation were 10\%, $0 \%$, and $5 \%$ in Mathieu group and $4 \%, 8 \%$, and $8 \%$ in Snodgrass group, respectively $(P>0.05)$. Success rate was $88 \%$ in Snodgrass group and $85 \%$ in Mathieu group $(P>0.05)$

Conclusion: In spite of some reports about preference for Snodgrass technique, we concluded that these techniques are as acceptable and as effective as each other for hypospodias repairing, regardless of cosmetic outcomes; however, we need further studies and larger sample sizes to determine which is the superior technique.

Aim of Study:To compare the outcomes of Mathieu and Snodgrass techniques in the repair of anterior distal hypospadiasConclusion: In spite of some reports about preference for Snodgrass technique, we concluded that apart from the cosmetic outcome which is in favor of Snodgrass repair, both techniques are as acceptable and as effective as each other for hypospadias repair and the essence of success depends on surgeons experience, fine suture materials and the use of well vascularized intermediate (covering) layer.
\end{abstract}

\section{INTRODUCTION}

Hypospadias is a common congenital anomaly of the penis in which the urethra opens proximal to its normal position at the tip of the glans. The term has been credited to Galenus and is derived from the Greek words hypo meaning "under" and spadon, indicating a "rent". Extending distally from the hypospadiac meatus is a strip of epithelium overlying connective tissues, the remnant of the unformed urethra, which in the past decade has been commonly referred to as the "urethral plate" In addition the penis with hypospadias typically has an incompletely formed prepuce and may exhibit ventral curvature. Therefore correction of the anomaly includes penile straightening, urethroplasty, glansplasty, and circumcision with the ultimate goal a functionally and cosmetically normal penis. (1)

Using modern surgical techniques this ideal can often be realized usually in a single procedure. It has not always been so Carl Beck reviewed the state of the art in 1917 when operations were done in two or more stages and concluded "It is not absolutely necessary to obtain a cosmetic result with smooth surfaces and a urethra in the center of the glans." Although he wrote just 30 years after the modern era of hypospadias surgery began, Beck already found that "the surgeon has to choose from a chaos of methods to find the proper one for his case, and without experience he often chooses the wrong method with subsequent failure." Since Beck's time operative techniques have continued to proliferate as the field of hypospadias surgery has grown to include not only proximal anomalies that were the original focus of intervention, but also the less severe distal lesions which are more common. Furthermore as late as 1981, Mills and colleagues still questioned the need for a meatus at the tip of the glans, having observed that "if the anatomically normal phallus is the goal of the surgeon and family, then they must be aware of the attendant risks of the techniques that accomplish this goal". $(1,2)$ 


\title{
Classification
}

The urologic literature identifies glanular, subcoronal, distal shaft, mid shaft, penoscrotal, scrotal, and perineal hypospadias although again the short comings of any preoperative classification must be recognized most boys with hypospadias have a subcoronal or proximal glanular meatus.

\section{Incidence}

Hypospadias is a common congenital anomaly. In fact a study of the 18 leading major birth defects in the United States (which notably did not include cryptorchidism) reported that hypospadias was the most common anomaly among whites, second most common among African Americans, and fourth most common among Hispanics .

Although the overall incidence of hypospadias is between $0.3 \%$ and $0.6 \%$ there is a significantly greater risk of the anomaly once it has occurred within a family.(3)

\section{Etiology}

Observations regarding racial and familial incidences suggest genetic factors inherited in a multifactorial fashion disorders of testosterone synthesis 5a-reduction to dihydrotestosterone or the structure or function of the androgen receptor as well as errors in postreceptor activity or the timing of androgen stimulation all theoretically could result in hypospadias. In that regard hypospadias may occupy one end of a spectrum which at the opposite extreme includes intersexuality.(4,5) Disordered testosterone production is implicated as a cause of hypospadias by the findings of several investigations Assuming normal hormone production, hypospadias could also result from deficient 5a-reductase type 2 conversion of testosterone to dihydrotestosterone.

Studies to determine the role of the androgen receptor in hypospadias originally characterized the receptor according to its physicochemical properties most notably androgen binding. Based on tissue cultures of genital skin, these investigations reported conflicting results some indicating decreased receptor levels while others yielded normal findings (6) In addition, defects in homeobox (Hox) genes might also adversely influence penile development. Hox genes regulate transcription and play an essential role in directing embryogenesis with Hox A and D clusters expressed in regionalized domains along the axis of the urogenital tract Another problem is recognized from investigations of possible links between environmental agents and hypospadias. The apparent upward trend of hypospadias reported during the past two decades has raised concerns of increased in utero exposure to progesterones, estrogens, or other antiandrogens. One recent report found a fivefold increased incidence of hypospadias in boys conceived by in vitro fertilization which might indicate disturbance of the maternal-fetal endocrine milieu by the progesterone therapy that accompanies assisted reproductive technology

\author{
Associated Anomalies \\ Cryptorchidism \\ Prostatic Utricle \\ Intersexuality
}

\section{Presentation and Evaluation}

Hypospadias is usually recognized during initial physical examination of the newborn. Typically, the abnormal prepuce calls attention to the anomaly and then further evaluation often finds the penile raphe displaced from the midline and the glans tilted downward. The meatus may appear pinhole in size but is not usually obstructive. Ventral curvature of the penile shaft may be noted during erection.(7) Although some boys with hypospadias have demonstrable endocrinopathies, intersex evaluations are generally limited to those with scrotal or perineal urethral openings and patients with both hypospadias and cryptorchidism $(8,9)$. In these situations, physical examination and the karyotype guide subsequent evaluation and therapy.Because proximal hypospadias interferes with both normal voiding and procreation, the need for reconstruction is not questioned. However parents not infrequently ask whether a subcoronal or proximal glanular defect justifies an operation. The authors are not aware of any study addressing the psychological impact of such anomalies if left untreated: Based on a variety of psychologic, anesthetic and surgical considerations the recommended age for hypospadias repair is between 6 and 18 months however the healthy term boy with an adequately sized phallus can safely undergo this procedure as day surgery as early as 3 months of age. Preterm infants initially have a higher risk for postanesthetic apnea, but elective day surgery can probably be accomplished by 5 months of age. (10) Pretreatment with androgen stimulation is sometimes considered especially in boys with a small phallus and proximal hypospadias. 


\section{SURGICAL REPAIR}

The goal of hypospadias surgery is to create a penis with both normal function and appearance. Because the anomaly includes a wide spectrum of severity, ranging from the glanular to perineal meatus in a penis that may be straight or significantly curved, it is not surprising that well over 200 operative techniques and variations have been described. The fact that the origins of nearly all of these procedures can be traced to the late 1800 s when surgical repair began in earnest attests to the difficulty of achieving a functional neourethra in a straight penis that appears to have only been circumcised.(11) In the past decade new concepts regarding the etiologies of penile curvature and the best means to correct it have gained acceptance. As a result the urethral plate is now more commonly preserved and incorporated into the urethroplasty. Together these developments have brought hypospadias surgery nearer its ultimate functional and cosmetic goals(12). The following section presents a brief overview of the history of hypospadiology to explain the evolution of its modern principles.(13)

\section{Urethroplasty}

Neourethras were first constructed from local skin flaps. Applying Thiersch's operation to hypospadias, Duplay made parallel longitudinal incisions from the meatus extending distally and rolled the skin into a tube covering this neourethra with lateral skin flaps.Nevertheless today the name Thiersch-Duplay is evoked when local skin is tubularized. It was the apparent need for additional tissues to form the neourethra or resurface the ventral penis that gave rise to literally hundreds of operations. Many Meanwhile, in 1896 van Hook may have been the first to tubularize a pedicle flap of preputial skin. Shortly thereafter Edmunds (14) introduced splitting the prepuce and transposing it ventrally for later tubularization. Byars (15) added a slight modification and today the term Byars' flaps describes the first of a two-stage repair. Another school of urethroplasty began with Ombrédanne's report of a U-shaped flap centered on the meatus which was drawn into a pouchlike neourethra by a single purse-string suture (15). Mathieu added some refinements, replacing the purse-string closure with parallel suture lines.Hodgson combined elements of the flip-flap and preputial pedicle flap in his various repairs. Furthermore he supported Devine and Horton's enthusiasm for one-stage repairs, which gradually replaced multistaged operations in the 1960s. Asopa and colleagues and Duckett further modified these techniques to describe tubularized preputial flaps and later the onlay flap . (16,17)The third school of urethroplasty is credited to Nové-Josserand. Before the late 1800 s trocars had been used to tunnel under the skin and through the glans to create a neourethra. Nové-Josserand placed tubularized skin grafts subcutaneously by this means.

One innovation without obvious connection to these French surgeons was meatoplasty and glansplasty or MAGPI. Introduced by Duckett in 1981 the operation was primarily intended for the subcoronal meatus (18). Previously such distal hypospadias usually had not been repaired because it rarely caused voiding or procreational difficulties but this relatively simple procedure with few complications offered the means to improve the appearance of the glans. Soon other techniques to repair more severe hypospadias came under increasing scrutiny as the standard for measuring success was raised to include not only functional outcomes but also the cosmetic results.(19,20)By the late 1980s, the hypospadiologist could rely on the MAGPI, flip-flap, or onlay and tubularized preputial flap to correct most abnormalities. However one problem with flip-flaps and onlays was the rounded horizontally oriented meatus that often resulted. Both Johanson and Avellán (20) and Rich and colleagues recognized that urethral plate configuration actually determined the cosmetic outcome because a flat plate yielded a horizontal meatus while a deeply grooved one produced a more normal, vertically orientated meatus. Consequently Rich and colleagues described "hinging" the flat plate by incising it distally to improve meatal cosmoses. A few months later Snodgrass extended this midline incision through the entire urethral plate and realized that the plate could then be tubularized without adding skin flaps. $(21,22,23)$

Regarding the high incidence of this anomaly and need for choosing appropriate treatment, the results and postoperative complications and outcome of Mathieu and Snodgrass techniques in patients with anterior distal hypospadias were compared in this study.

\section{MATERIALS AND METHODS}

In a randomized prospective study from march 2012 to march 2013, 45 boys with the age of (range 1 to 12) years with anterior hypospadias, were assigned into two groups to undergo either Snodgrss or Mathieu surgical repair In surgical specialties hospital Medical city Baghdad . Inclusion criteria were anterior and distal shaft hypospadias and age of 12 years or less, and exclusion criteria were association with chordee, history of circumcision, and surgical repair history.On a randomized basis, 20 patients underwent surgical repair using Mathieu technique and 25 patients using Snodgrass technique. All surgeries were performed by one single surgeon who was experienced enough to do both surgeries, with different supervisors . Surgical instruments, suture materials (5-0 Vicryl) and urinary diversion (urethral Foleys catheter $6 \mathrm{~F}$ to $10 \mathrm{~F}$ ) were the same for all patients. 
The protective pedicle layer from dartos muscle covered the suture line in all patients and bipolar cautery would used, when it was necessary. All of the patients were examined 1 week,and1 month after discharge. Data including duration of the surgery, stenting time, duration of hospitalization, and any kind of complications such as break down, meatal stenosis, and fistula formation were collected. Also, success rate was calculated for every single patient. The information related to operation along with findings in follow-ups were recorded in forms and they were compared between the two groups.

\section{Surgical techniques}

\section{Snodgrass:}

A) A 3- 0 silk suture is place into the glans for traction and to later secure the urethral stent. The initial skin incision. care is taken to preserve sufficient inner prepuce so that a so-called 'mucosal collar' can be approximated in the ventral midline after glansplasty. Then the penis is degloved to near the penoscrotal junction

B) Next, longitudinal incisions are made along the visible junction of the glans wings to the urethral plate.

C) The key step in the procedure is midline incision of the urethral plate. This manoeuvre is facilitated by counter-traction maintained by the surgeon and assistant along opposite margins of the plate. Using tenotomy scissors, the relaxing incision is made from within the meatus to the tip of the urethral plate A 6 F Silastic stent is passed into the bladder and secured to the glans traction suture. Then the urethral plate is tabularized beginning at the neomeatus, using 5-0 vicryl suture.

D) A dartos pedicle flap is dissected from the preputial hood or shaft skin

E) Glansplasty F) Skin closures also use 5-0 vicryl sutures

\section{Mathieu, perimeatal-based flap}

starts with measuring the length of the defect from the urethral meatus to the glans tip. An equal distance from the meatus is measured on the proximal penile shaft skin. With the aid of calipers, the urethral plate and perimeatal-based flap are then marked at appropriate widths. Typically, a width of $7.5 \mathrm{~mm}$ is measured for the proximal flap. This width is tapered to $5.5 \mathrm{~mm}$ at the distal extent of the glans, and longitudinal lines outlining the urethral plate are then drawn. A line is marked beginning at either lateral margin of the previously marked urethral plate and carried around the dorsal aspect of the penis 5 to $7 \mathrm{~mm}$ proximal to the corona of the glans. Glans wings are incised deeply, the penile shaft skin is degloved, and the penis is evaluated for curvature. This tissue is folded over at the meatus (perimeatal-based flap), and bilateral, longitudinal, running subcuticular sutures approximate this flap to the lateral aspects of the urethral plate, thereby creating the neourethra. Tubularization is performed over a 6-10 Fr Silastic catheter using 5-0 vicryl suture. The meatus is matured at the glans tip with simple, interrupted, fine absorbable suture, and second-layer neourethral coverage is performed with dorsal dartos tissue. The glans wings are then approximated without tension in two layers, and skin coverage is completed.

\section{Statistical Analysis:}

Statistical Package for Social Sciences version 17 (SPSS v.17) used for data input and analysis. Discrete variables presented as numbers (counts) and percents (\%). Continuous Variables presented as Mean and standard deviation (SD). T-test for two independent samples used to test the significant of difference between two independent continuous variables. Chi square test for independence used to test the significance of association between discrete variables. $\mathrm{Z}$ test for difference in proportion used to test the significance of difference between proportions. Findings with $\mathrm{P}$ values less than 0.05 were considered significant.

\section{The Results}

\begin{tabular}{|c|c|c|c|}
\hline \multirow[b]{2}{*}{ Variables } & \multicolumn{2}{|c|}{ Method } & \multirow[b]{2}{*}{$P$ value } \\
\hline & $\begin{array}{c}\text { Snodgrass } \\
\mathbf{N}=\mathbf{2 5} \\
\end{array}$ & $\begin{array}{c}\text { Mathieu } \\
\mathbf{N}=\mathbf{2 0} \\
\end{array}$ & \\
\hline Age of Patients (year); Mean \pm SD & $6.7 \pm 4.4$ & $6.8 \pm 4.5$ & 0.941 \\
\hline $\begin{array}{cc}\text { Type of Hypospadias; } \mathbf{N}(\%) \\
-\quad \text { Distal Shaft } \\
-\quad & \text { Subcoronal } \\
- & \text { Coronal }\end{array}$ & $\begin{array}{l}17(68.0) \\
6(24.0) \\
2(8.0)\end{array}$ & $\begin{array}{l}10(50.0) \\
3(15.0) \\
7(35.0)\end{array}$ & 0.078 \\
\hline Operation Time (minute); Mean \pm SD & $106 \pm 23$ & $74 \pm 26$ & 0.000 \\
\hline
\end{tabular}




\begin{tabular}{|c|c|c|c|}
\hline Stenting Time(days); Mean \pm SD & $6.3 \pm 0.8$ & $5.8 \pm 1.1$ & 0.084 \\
\hline Success Rate; N (\%) & $22(88.0 \%)$ & $17(85.0 \%)$ & 0.883 \\
\hline $\begin{array}{cc}\text { Complications; } & \mathbf{N}(\%) \\
- & \text { Total }\end{array}$ & $5(20.0 \%)$ & $3(15.0 \%)$ & 0.965 \\
\hline $\begin{array}{c}- \\
-\quad \text { Meatal Stenosis }\end{array}$ & $2(8.0 \%)$ & $0(0.0 \%)$ & 0.571 \\
\hline - Urocutaneous Fistula & $2(8.0 \%)$ & $1(5.0 \%)$ & 0.841 \\
\hline - Wound Dehiscence & $1(4.0 \%)$ & $2(10.0 \%)$ & 0.841 \\
\hline
\end{tabular}

Table 1: Distribution of study sample according to type of surgical method used, age, type of hypospadias and to factors related to the operation.No significant difference in age time between the patients of the two methods ( $P$ $>0.05$, table1). No significant association between the type of hypospadias and the method used $(\mathrm{P}>0.05$, table1).The operation time was significantly longer in Snodgrass method than Mathieu method $(\mathrm{P}<0.05$, table 1). Which may be due to use of preputial dartos flap as covering second layer in most of Snodgrass technique patients, and there was 68\% distal shaft hypospadias in Snodgrass technique vs. 50\% in Mathieu technique arm. No significant difference in stenting time between the patients of the two methods $(\mathrm{P}>0.05$, table 1$)$. There was no significant difference in the success rate between the two methods $(\mathrm{P}>0.05$, table1) There was no significant difference in the proportion of all/any of the observed complication(s) $(\mathrm{P}>0.05$, table1) There was no significant correlation between certain hypospadias site and success rate. The cosmetic outcome was better in Snodgrass technique regarding meatal shape and location .

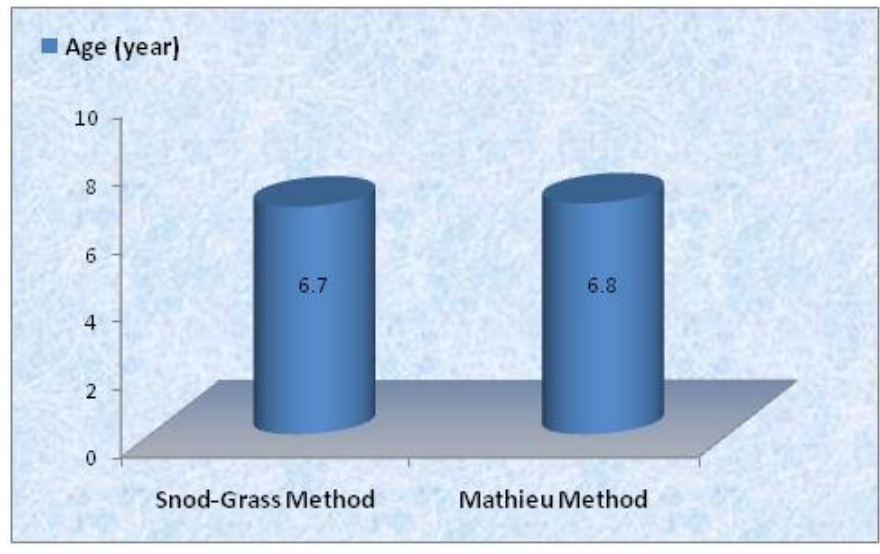

Figure 1: Mean age of patients according to the selected method of intervention.

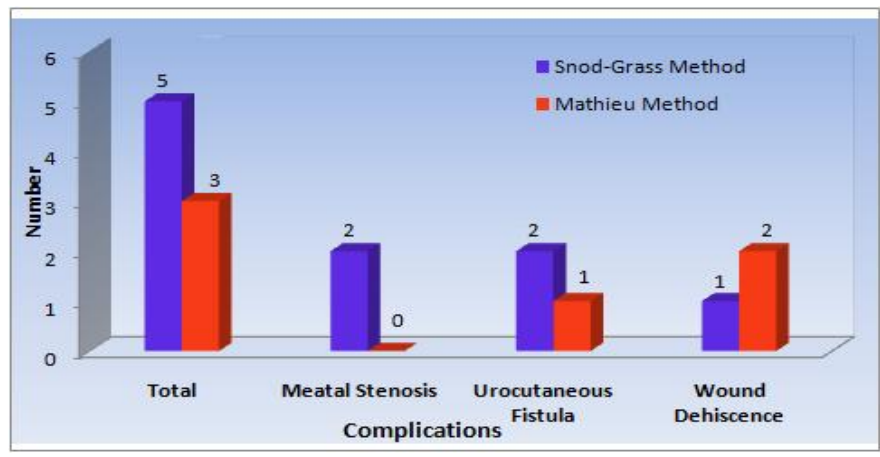

Figure 2: Distribution of cases according to method used and resultant complications.

\section{DISCUSSION}

Hypospadias is a congenital anomaly in which meatal orifice opens to vental part of penis instead of the glans apex, because of a defect in urethral development. Its incidence rate is about 1 in 250 male live births. About $50 \%$ to $70 \%$ of hypospadias cases are the anterior types. 
Several surgical techniques have been advocated for repairing anterior hypospadias. Some of these techniques are MAGPI, Mathieu, Arap, Snodgrass, Mustard, and Barcat, among which Mathieu and Snodgrass are the most commonly used techniques. $(24,25)$ In Sariyuce and coworkers' study on 52patients who were operated on using modified Mathieu technique, they used delicate instruments and surgical materials and a 2.5fold magnification. Complication rate was 5.8\% (3 patients) and fistula formation rate was $1.9 \%$ (1 patient). Hence, they concluded that anterior hypospadias repair using Mathieu technique and delicate instruments, is completely successful. However, in multivariate analysis, only time period difference was significant. Consequently, this study suggests that surgeon's experience is a very important factor in success rate of hypospadias repairing, and they recommend to the surgeons not to change their technique unless they are familiar enough with another technique. (26) Holland et al performed a study on 59 patients with a mean age of 13 months, using Snodgrass technique, and followed them for 9 months. Glandular meatus, conic form of glans, steady urinary outflow, fistula, and meatal stenosis were reported in $97 \%, 98 \%, 89 \%, 10 \%$, and $5 \%$ of cases, respectively. Appearance and functional results were reported to be acceptable. (27) Decter et al performed a study on 197 patients and reported that fistula was seen in $6.4 \%$ of patients for whom adjacent tissue had been used to cover urethroplasty, and it was seen in $0.8 \%$ of those for whom pediculated tissue had been used. They concluded that in case of using Snodgrass technique, fistula formation is very rare if we use vascularized pedicle to cover neourethra, and Snodgrass method is the best technique for hypospadias repairing. (28)

In some studies, these two techniques were compared with each other. For example, in the study by Imamoglu et al, 56 patients were operated on using Snodgrass technique and 54 patients were operated on using Mathieu technique. They were followed for 24 months. These two groups had no significant difference demographically. Meatal stenosis, fistula formation, wound dehiscence, and flap necrosis were reported in 2, 4, 2, and 2 patients with Mathieu method, and 5, 4,3, and 0 patients with Snodgrass method, respectively. Wound dehiscence and flap necrosis were the rarest complications and meatal stricture was the most common complication in patients who were operated on using Snodgrass technique and a significant statistical difference was seen. No significant difference was seen between these two groups in fistula formation rate. Mean hospitalization period, stent removing time, and catheterization time were significantly lower in patients who had been operated on using Mathieu technique. Success rate was reported the same (78.6\% in Snodgrass and $77.8 \%$ in Mathieu), but cosmetic appearance was obviously better in Snodgrass technique. They concluded that if the urethral plate is intact, Snodgrass technique will be preferable and if not, Mathieu technique will be much better (29).

Moradi et al 31 ( 2 cases of fistulas and 1 meatal stenosis); whereas, only one patient experienced glandular dehiscence in Snodgrass technique group. In all patients who had been operated on using Snodgrass technique, meatal appearance was slit like; whereas, in patients who had been operated on using Mathieu technique, meatus was rounded and horizontal. They concluded that Snodgrass technique is accompanied by better results and more natural meatal appearance. As it was shown in the above studies, the success of hypospadias repairing operation depends on flap circulation, type and quality of suture, instruments used, neourethral protecting cover, and the surgeons' experience, and both methods have had acceptable results. General agreement about glans appearance is in favor of Snodgrass technique. (30) In our study, regarding the surgeon's enough experience in both techniques, using delicate instruments and sutures (5-0 Vicryl), using bipolar cautery on need, and hypospadias repairing basics consideration. The operation time was significantly longer in Snodgrass method than Mathieu method ( $\mathrm{P}<0.05$, table 1). There was no significant difference in the success rate between the two methods $(\mathrm{P}>0.05$, table 1$)$, which is comparable to the above mentioned studies.

There was no significant difference in the proportion of all/any of the observed complication(s) $(\mathrm{P}>0.05$, table1). however, there were two suture lines in Mathieu technique. In our study, duration of surgery was a little more than that in other studies, especially for Snodgrass group. In the present study penile appearance was cosmetically better in Snodgrass group.

\section{REFERENCES}

[1.] Beck C. Hypospadias and its treatment. SGO 1917;14:511.

[2.] Mills C, McGovern J, Mininberg D, et al. An analysis of different techniques for distal hypospadias repair: the price of perfection. J Urol 1981;125:701.

[3.] Paulozzi LJ, Erickson JD, Jackson RJ. Hypospadias trends in two US surveillance systems. Pediatrics 1997;100:831.

[4.] Nonomura K, Fuijeda K, Sakakibara N, et al. Pituitary and gonadal function in prepubertal boys with hypospadias. J Urol 1984;132:595.

[5.] Allen TD, Griffin JE. Endocrine studies in patients with advanced hypospadias. J Urol 1984;131:310.

[6.] Wiener JS, Teague JL, Roth DR, et al. Molecular biology and function of the androgen receptor in genital development. J Urol 1997; $157: 1377$

[7.] Smulian JC, Scorza WE, Guzman ER, et al. Prenatal sonographic diagnosis of midshaft hypospadias. Prenat Diagn 1996;16:276

[8.] Grumbach MM, Conte FA. Disorders of sex differentiation. In: Wilson JD, et al., eds. Williams' textbook of endocrinology, ed 9. Philadelphia: Saunders, 1998.

[9.] Smith EP, Wacksman J. Evaluation of severe hypospadias. J Pediatr 1997;131:344. 
[10.] Cote CJ, Zaslavsky A, Downes JJ, et al. Postoperative apnea in former preterm infants after inguinal herniorrhaphy: a combined analysis. Anesthesiology 1995;82:809.

[11.] Backus LH, DeFelice CA. Hypospadias—-then and now. Plast Reconstr Surg 1960;25:146

[12.] Browne D. An operation for hypospadias. Proc Roy Soc Med 1949;41:466.

[13.] van Hook W. A new operation for hypospadias. Ann Surg 1896;23:378.

[14.] Edmunds A. An operation for hypospadias. Lancet 1913;1:447.

[15.] Byars LT. A technique for consistently satisfactory repair of hypospadias. SGO 1955;100:184

[16.] Asopa HS, Elhence IP, Atri SP, et al. One stage correction of penile hypospadias using a foreskin tube. Int Surg 1971;55:435.

[17.] Duckett JW. Transverse preputial island flap technique for repair of severe hypospadias. Urol Clin North Am 1980;7:423.

[18.] Duckett JW. MAGPI (meatoplasty and glansplasty): a procedure for subcoronal hypospadias. Urol Clin North Am 1981; 8:513.

[19.] Belman AB. Hypospadias and other urethral abnormalities. In: Kelalis PP, King LR, Belman AB, eds. Clinical pediatric urology, ed 3. Philadelphia: Saunders, 1992.

[20.] Johanson B, Avellán L. Hyposopadias: a review of 299 cases operated 1957-69. Scand J Plast Reconstr Surg 1980;14:259.

[21.] Rich MA, et al. Hinging the urethral plate in hypospadias meatoplasty. J Urol 1989;142:1551.

[22.] 22. Snodgrass W. Tubularized, incised plate urethroplasty for distal hypospadias. J Urol 1994;151:464.

[23.] 23. Retik AB, Borer JG. Hypospadias. In: Walsh PC, Retik AB, Vaughan ED Jr, et al, editors. Campbell's urology. 8th ed. Philadelphia: WB Saunders; 2002. p.2284-333.

[24.] Duckett JW. Hypospadias. In: Walsh PC, Retik AB, Stamey TA, Vaughn ED Jr, et al, editors. Campbellō'sm Urology. 7th ed. Philadelphia: WB Saunders; 1998.p.2093-116..

[25.] Sariyuce O, Roth DR, Gonzales ET Jr. Distal hypospadias repair with meatal-based flaps on an outpatient basis. Int Urol Nephrol. 1997;29:241-4.

[26.] Uygur MC, Erol D, Germiyanoglu C. Lessons from 197 Mathieu hypospadias repairs performed at a single institution. Pediatr Surg Int. 1998;14:192-4.

[27.] Holland AJ, Smith GH, Cass DT. Clinical review of the 'Snodgrass' hypospadias repair. Aust N Z J Surg. 2000;70:597-600.

[28.] Decter RM, Franzoni DF. Distal hypospadias repair by the modified Thiersch-Duplay technique with or without hinging the urethral plate: a near ideal way to correct distal hypospadias. J Urol. 1999;162:1156-8.

[29.] Imamoglu MA, Bakirtas H. Comparison of two methods--Mmathieu and Snodgrass--in hypospadias perimeatal-based flap (Mathieu) and the tabularized repair. UrolInt. 2003;71:251-4.

[30.] Oswald J, Korner I, Riccabona M. Comparison of the incised-plate urethroplasty (Snodgrass) in primary distal hypospadias. BJU Int. 2000;85:725-7.

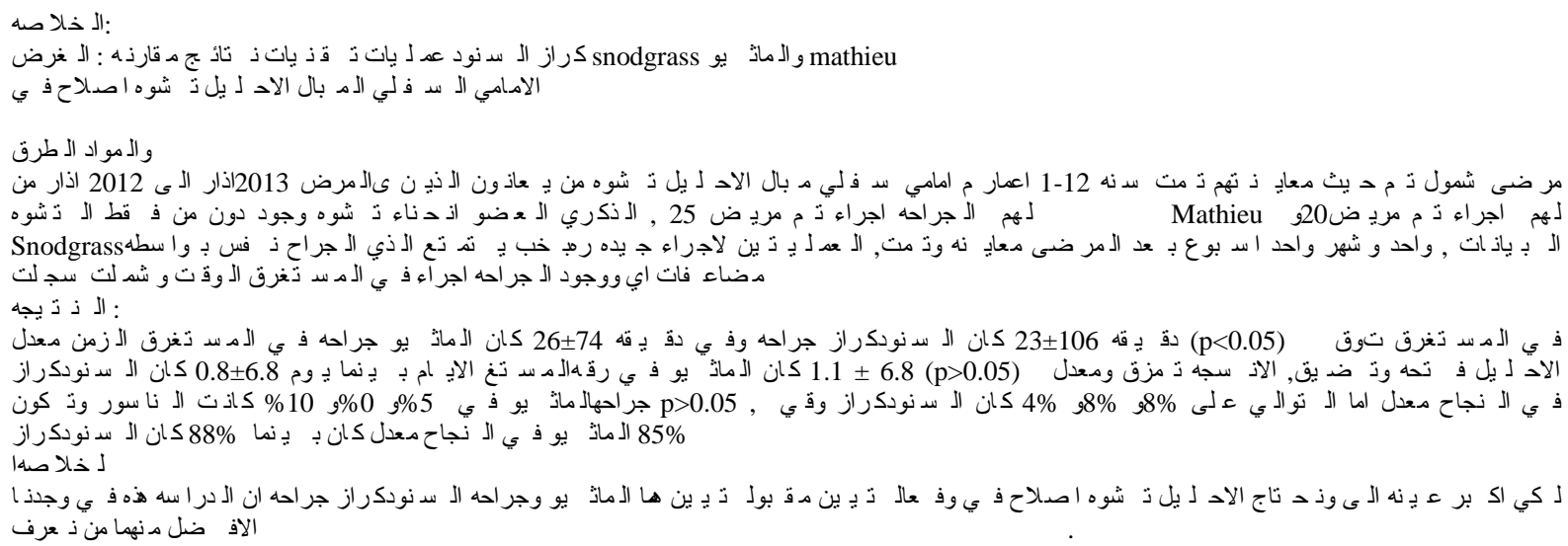

